- Describes medial diastema aetiology, and the right time to correct it.

- A foreign body in the periodontal space must be suspected when an unusual clinical attachment level loss occurs in childhood.

\title{
Loss of a clinical attachment level in a child: differential diagnosis with aggressive periodontitis. Case report
}

\author{
A. Sánchez-Pérez, ${ }^{1}$ M. J. Moya-Villaescusa, ${ }^{2}$ M. C. Gambín-Manzano ${ }^{3}$ and L. A. Bravo-González ${ }^{4}$
}

A nine-year-old boy presented with a serious periodontal lesion caused by a rubber band that had been used to close a medial diastema. Surgery was required to remove it. The impaction of a foreign body in the periodontal space should be suspected when a clinical attachment level is lost during childhood.

\section{CASE REPORT}

A family attended the dental hospital concerned about the unhealthy appearance of their nine-year-old child's upper incisors. The patient had no dental background of any importance, without trauma, infection history or abnormal behaviour. Examination revealed mixed dentition. The gingiva of both upper incisors was severely inflamed and intense erythema reached as far as the attached gingiva. The area bled spontaneously and the incisors showed grade $2+$ mobility. The probing depth was $9 \mathrm{~mm}$ on the distal face of both (Fig. 1). A complete periodontal study was performed; no other teeth were affected.

The presence of a divergent central diastema led to the suspicion that the cause of the lesion might be irregular orthodontic treatment. The parents confirmed that

1,"2Professors of Periodontics, Clínica Odontológica Universitaria, Hospital Morales Meseguer, Universidad de Murcia, C/ Marqués de los Vélez s/n, 30008 Murcia, Spain: ${ }^{3}$ Odontologist, C/ Mayor $20-1{ }^{\circ} \mathrm{C}$, Puebla de Soto 30836 Murcia, Spain; ${ }^{4}$ Professor of Orthodontics, Clinica Odontológica Universitaria, Hospital Morales Meseguer, Universidad de Murcia, C/ Marqués de los Vélez s/n 30008 Murcia, Spain

${ }^{*}$ Correspondence to: Arturo Sánchez Pérez Email:arturosa@um.es

\section{Refereed Paper}

Accepted 8 March 2006

DOI: $10.1038 /$ sj.bdj.4813972

(c) British Dental Journal 2006; 201: 281-282 the child had received orthodontic treatment from a 'family friend', but that this had been abandoned about a month ago.

\section{TREATMENT}

With a diagnosis of presumed secondary periodontal trauma caused by orthodontic rubber bands, an exploratory full-thickness flap was lifted to expose the offending article in the region of the third apical of the central incisors (Fig. 2). The rubber band was removed and the root surfaces gently cleaned. The flap was replaced and sutured with silk.

The post-operatory period proceeded normally and the sutures were removed after one week. The patient was monitored at one month, three months, six months and one year. A notable improvement was seen by the end of follow-up. The probing depth was reduced to $3 \mathrm{~mm}$, and the loss of clinical attachment level was $4 \mathrm{~mm}$ (an improvement of $4 \mathrm{~mm}$ ). The incisors showed grade $1+$ residual mobility.

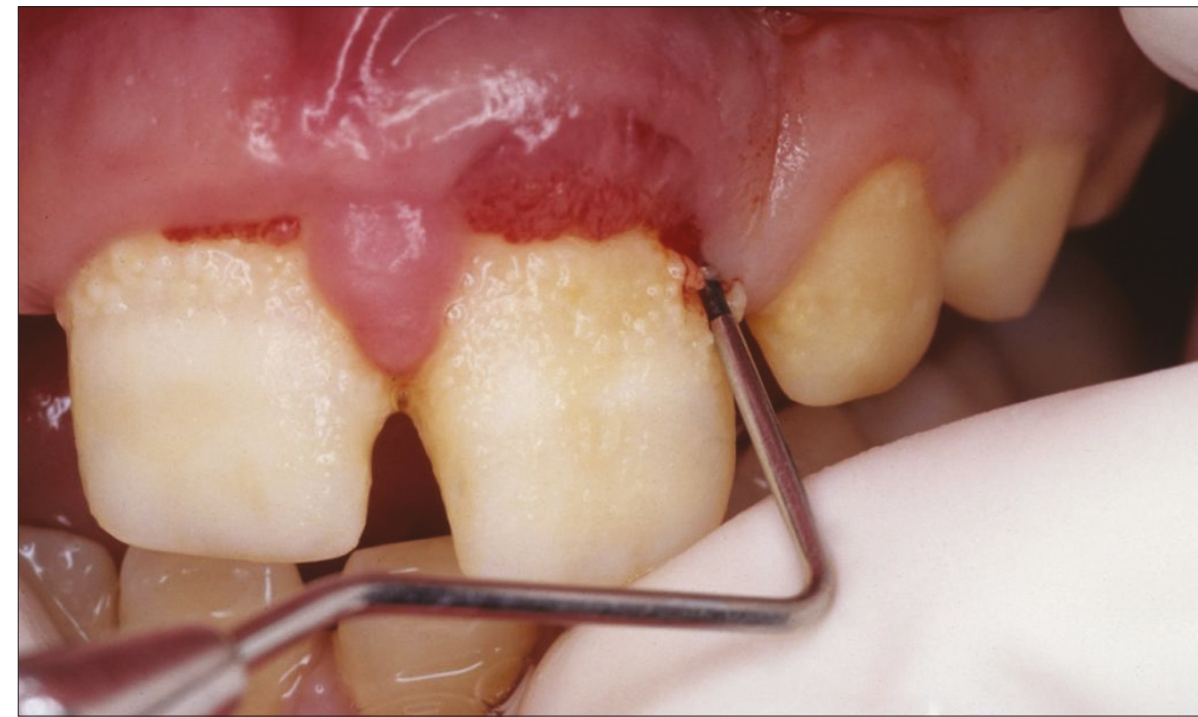

Fig. 1 The distal probing depth for both central incisors was $9 \mathrm{~mm}$. 


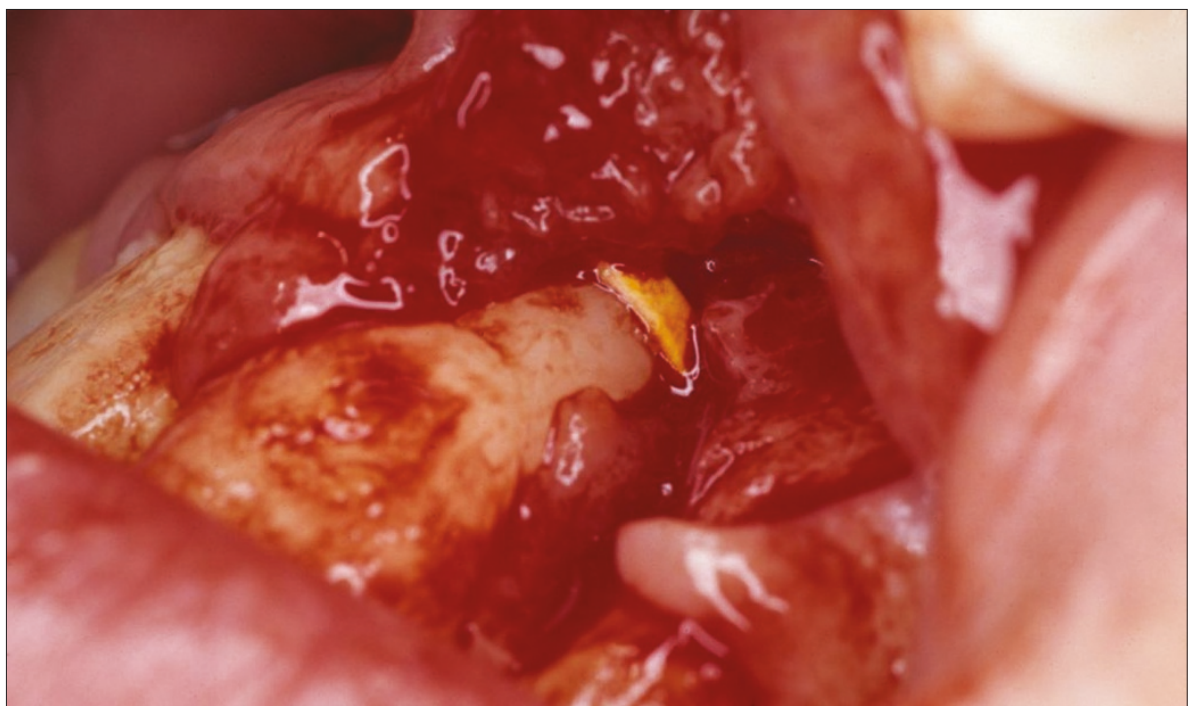

Fig. 2 Full-thickness flap lifted to reveal a rubber band 2/3 of the way down the root.

\section{DIFFERENTIAL DIAGNOSIS}

The differential diagnosis of periodontal lesions affecting young children is particularly important because of possible consequence. An early and accurate diagnosis is essential if complications are to be avoided. Four possible causes should be considered:

1. Aggressive periodontitis:

Generalised forms or local forms.

2. Periodontitis as a manifestation of a haematological or systemic disease: This diagnosis can be discarded when the patient has no history of any health problem normally associated with periodontitis.

3. Self-inflicted periodontal lesions: The lack of specific proof of such behaviour makes it difficult to arrive at this diagnosis.

4. Presence of a foreign body: Many of the most common foreign bodies involved in this kind of lesion (such as orthodontic rubber bands) are radio-transparent.

\section{COMMENT}

The iatrogenic loss of a clinical attachment level caused by interdental rubber bands was first described in $1870 .{ }^{1}$ Rubber bands are so effective at causing exfoliation that years ago they were proposed as an atraumatic extraction method for patients with psychological or coagulation problems. ${ }^{2,3}$

A medial diastema has a multifactorial aetiology but can involve the insertion of the labial frenum, oral respiratory habits, muscular imbalances, the physical interposition of the tongue or a foreign object, abnormalities of maxillary structure, and dental imbalances and abnormalities. Its frequency is clearly influenced by age, varying from $46 \%$ at five years of age to only 5.3\% at 15 years of age. Racial differences can also play a part in its appearance (it is more common in black people), as can gender, environmental and hereditary factors. ${ }^{4}$

Central diastemas are common at this age and can be considered quite normal. They tend to close with the eruption of the lateral incisors and later of the canine teeth. Diastemas of $2 \mathrm{~mm}$ tend to close spontaneously; however, those wider than $2 \mathrm{~mm}$ may not close completely by the time eruption is complete.

At least six techniques have been reported for closing central diastema, but the use of orthodontic rubber bands on their own with no mechanical retention mechanism is completely contraindicated.

The present case shows that, probably through a lack of information, many people still seek health services from nonqualified persons whose skills and ethics are questionable. It is often argued that these persons provide the same service with the same quality but at a lower price. The truth, however, is that their work lacks any guarantee of quality and in the long run represents no economic saving. As shown by the present case, the cost to the patient's wellbeing can be high - perhaps irrecoverable.

Finally, we want to alert dental practitioners that the most likely reason for loss of attachment in children, who are otherwise fit and healthy, is the presence of a foreign body in the periodontal space, although we have to do a differential diagnosis with other periodontal lesions affecting young children.

1. McQuillen J H. Care in the use of India-rubber rings. Dent Cosmos 1870; 12: 429-430.

2. Dalitsch W W. Dental extraction in hemophilia. J Am Dent Assoc 1934: 21: 1804-1811.

3. Massler M, Aguirre B. Exfoliation of teeth by means of elastic bands. J Dent Child 1952; 19: 56-59.

4. Huang W J, Creath C J. The midline diastema: review of its etiology and treatment. Pediatr Dent 1995; 17: 171-179. 